\title{
Patient-derived xenograft models of colorectal cancer in pre- clinical research: a systematic review
}

\author{
Kai M. Brown ${ }^{1,2,3}$, Aiqun $X^{3}{ }^{3}$, Anubhav Mittal ${ }^{1,2,3}$, Jaswinder S. Samra ${ }^{1,2}$, Ross \\ Smith $^{3}$ and Thomas J. Hugh ${ }^{1,2,3}$ \\ ${ }^{1}$ Northern Clinical School, University of Sydney, Sydney, New South Wales, Australia \\ 2 Upper GI Surgical Unit, Royal North Shore Hospital and North Shore Private Hospital, Sydney, New South Wales, Australia \\ ${ }^{3}$ Cancer Surgery and Metabolism Research Group, The Kolling Institute of Medical Research, Royal North Shore Hospital, \\ Sydney, New South Wales, Australia \\ Correspondence to: Kai M. Brown, email:kkai6773@uni.sydney.edu.au \\ Keywords: patient-derived xenograft, colorectal cancer, systematic review, PDX, animal model \\ Received: February 07, $2016 \quad$ Accepted: July 18, $2016 \quad$ Published: August 10, 2016
}

\section{ABSTRACT}

AIMS: We sought to objectively assess the internal and external validity of patient-derived xenograft (PDX) models as a platform in pre-clinical research into colorectal cancer (CRC). Metastatic disease is the most common cause of death from CRC, and despite significant research, the results of current combination chemotherapy and targeted therapies have been underwhelming for most of this patient group. One of the key factors limiting the success of translational CRC research is the biologically inaccurate models in which new therapies are developed.

METHODS: We used the PRISMA (Preferred Reporting Items for Systematic Reviews and Meta-Analyses) checklist and SYRCLE (Systematic Review Centre for Laboratory animal Experimentation) guidelines to search Ovid MEDLINE and Embase databases up to July 2015 to identify studies involving PDX models of CRC where the model had been validated across multiple parameters. Data was extracted including host mouse strain, engraftment rate, site of engraftment, donor tumour source and development of metastases in the model.

RESULTS: Thirteen articles satisfied the inclusion criteria. There was significant heterogeneity amongst the included studies, but overall the median engraftment rate was high (70\%) and PDX models faithfully recapitulated the characteristics of their patient tumours on the microscopic, genetic and functional levels.

CONCLUSIONS: PDX models of CRC have a reasonable internal validity and a high external validity. Developments in xenografting technology are broadening the applications of the PDX platform. However, the included studies could be improved by standardising reporting standards and closed following the ARRIVE (Animals in Research: Reporting In Vivo Experiments) guidelines.

\section{INTRODUCTION}

Colorectal cancer (CRC) is the third most common cancer and the fourth most common cause of cancer death worldwide $[1,2]$. Over $55 \%$ of the global burden of disease occurs in developed countries and overall 5 -year survival rates are approximately $65 \%{ }^{3}$. Metastatic disease is the most common cause of death, and although resection can cure most patients with stage I cancer, $40 \%$ of patients with stage II-III cancer will develop metachronous, locoregional or distally recurrent cancer
$[3,4]$. Furthermore, up to $20 \%$ of patients have metastatic disease on presentation, most commonly in the liver [5]. Despite enormous international efforts to discover new therapeutic strategies for CRC, current treatments with combination chemotherapy and targeted monoclonal antibodies have not dramatically changed overall survival rates. Frustratingly, up to $95 \%$ of new drugs that eventually get to Phase III trials ultimately are shown to be ineffective in humans [6].

One factor likely to play a role in the failure of phase III trials is the biologically inaccurate pre-clinical models 
Table 1: Fully validated Patient-Derived Xenograft Models of Colorectal Cancer

\begin{tabular}{|c|c|c|c|c|c|c|c|c|c|c|}
\hline \multirow[b]{2}{*}{ First Author } & \multirow[b]{2}{*}{ Year } & \multirow{3}{*}{$\begin{array}{c}\text { Total } \\
\text { number of } \\
\text { patient } \\
\text { tumours } \\
\text { engrafted } \\
35\end{array}$} & \multicolumn{2}{|c|}{$\begin{array}{c}\begin{array}{c}\text { Graft Source } \\
\text { (engraftment rate) }\end{array} \\
\end{array}$} & \multirow{2}{*}{$\begin{array}{l}\text { Overall } \\
\text { engraftment } \\
\text { Rate }\end{array}$} & \multirow{2}{*}{$\begin{array}{c}\text { Number of } \\
\text { P1 mice } \\
\text { grafted per } \\
\text { patient }\end{array}$} & \multirow{2}{*}{$\begin{array}{l}\text { Size of graft ( } \mathrm{mm}^{3} \\
\text { or cell number) }\end{array}$} & \multirow[b]{2}{*}{ Mouse Strain } & \multirow{2}{*}{$\begin{array}{c}\text { Xenograft } \\
\text { Type } \\
\text { (Heterotopic } \\
\text { vs } \\
\text { Orthotopic) }\end{array}$} & \multirow{2}{*}{$\begin{array}{c}\text { Metastases } \\
\text { generated } \\
\text { in model }\end{array}$} \\
\hline & & & $\begin{array}{l}\text { Primary } \\
\text { CRC }\end{array}$ & $\begin{array}{l}\text { mCRC } \\
\text { tumour }^{\#}\end{array}$ & & & & & & \\
\hline Fichtner[61] & 2004 & & $33^{*}$ & $2^{*}$ & $\begin{array}{l}43 \%(>3 \\
\text { passages) }\end{array}$ & $6-8$ & 25 & $\mathrm{nu} / \mathrm{nu}$ & Heterotopic & \\
\hline Dangles-Marie[44] & 2007 & 26 & $10(90 \%)$ & $16(69 \%)$ & $77 \%$ & 5 & Not specified & $\mathrm{nu} / \mathrm{nu}$ & Heterotopic & \\
\hline Mischek[67] & 2009 & 10 & \multicolumn{2}{|c|}{ All metastases } & $60 \%$ & 3 & $\begin{array}{c}8 \\
\text { (then disassociated } \\
\text { into suspension) }\end{array}$ & SCID/beige & Heterotopic & \\
\hline Linnebacher[46] & 2010 & 48 & \multicolumn{2}{|c|}{ All primary } & $\begin{array}{l}72 \% \text { overall } \\
\text { ( } 71 \% \text { from } \\
\text { cryopreserved) }\end{array}$ & $6-8$ & 27 & $\begin{array}{c}\text { NOD/SCID and } \\
n u / n u\end{array}$ & Heterotopic & \\
\hline Bertotti[47] & 2011 & 150 & \multicolumn{2}{|c|}{ All metastases } & $87 \%$ & 2 & Not specified & NOD/SCID & Heterotopic & \\
\hline $\operatorname{Jin}[48]$ & 2011 & 1 & \multicolumn{2}{|c|}{$\begin{array}{l}\text { Matched primary and } \\
\text { metastasis }\end{array}$} & $\begin{array}{l}60 \% \text { primary } \\
80 \% \text { liver met }\end{array}$ & 20 & 12 & BALB/c nude & Heterotopic & \\
\hline $\operatorname{Kim}[50]$ & 2012 & 20 & $\begin{array}{c}2 \\
\text { successful }\end{array}$ & $\begin{array}{c}12 \\
\text { successful* }\end{array}$ & $70 \%$ & 5 & $\begin{array}{c}8-27 \\
\text { (then disassociated } \\
\text { into suspension) }\end{array}$ & NOD/SCID & Heterotopic & \\
\hline Julien[34] & 2012 & 85 & $58(60.3 \%)$ & $27(70 \%)$ & $64 \%$ & 2 & 50 & nude & $\begin{array}{l}\text { Heterotopic, } \\
41 \text { orthotopic } \\
\text { in parallel }\end{array}$ & $\begin{array}{l}32 \% \text { of } \\
\text { ortho }\end{array}$ \\
\hline Monsma[40] & 2012 & 18 & \multicolumn{2}{|c|}{ All primary } & $50 \%$ & Up to 5 & $\leq 3 \mathrm{~mm}$ long axis & $\mathrm{nu} / \mathrm{nu}$ & Heterotopic & \\
\hline Puig[36] & 2013 & 40 & $32(84 \%)$ & $8(100 \%)$ & $88 \%$ & $\begin{array}{c}\text { Not } \\
\text { specified }\end{array}$ & $\begin{array}{c}1 \times 10^{5} \text { cells }\left(1 \times 10^{6}\right. \\
\text { for orthotopic) }\end{array}$ & NOD/SCID & $\begin{array}{c}6 \mathrm{x} \\
\text { Orthotopic }\end{array}$ & Yes \\
\hline Chou[43] & 2013 & 50 & $34(53 \%)$ & $16(56 \%)$ & $58 \% * *$ & $\begin{array}{c}\text { Not } \\
\text { specified }\end{array}$ & $\begin{array}{c}1 \times 10^{4}-2 \times 10^{6} \\
\text { cells }\end{array}$ & NSG & Heterotopic^^ & \\
\hline Lee[42] & 2014 & 10 & \multicolumn{2}{|c|}{ All primary } & $100 \%$ & $\begin{array}{c}\text { Not } \\
\text { specified }\end{array}$ & 10 & $\begin{array}{c}\mathrm{BALB} / \mathrm{c} \mathrm{nu} / \mathrm{nu} \\
\text { or NOD/SCID } \\
\text { mice }\end{array}$ & Heterotopic & \\
\hline Cho[49] & 2014 & 143 & \multicolumn{2}{|c|}{$\begin{array}{l}\text { Mixed primary and } \\
\text { metastases, numbers not } \\
\text { specified }\end{array}$} & $67 \%$ & $5-6$ & $1-2$ & $\mathrm{BALB} / \mathrm{c}$ nude & Heterotopic & \\
\hline
\end{tabular}

\# mCRC - metastatic colorectal cancer

* Authors did not stratify engraftment rate according to tumour source

^ 46 specimens subcutaneously grafted into the flank, 14 heterotopically grafted into the subrenal capsule

** 33 of 57 surgical specimens from 27 out of 50 individual patients were engrafted

in which many drugs are developed [7-9]. Although there is no widely accepted tool to score the effectiveness of a given biological model $[10,11]$, it is possible to assess worth based on compliance with the ARRIVE (Animals in Research: Reporting In Vivo Experiments) guidelines [12] and the ability to maintain internal and external validity [13]. Internal validity refers to an experiment's ability to identify causal relationships and partly depends on being able to control for confounders. External validity refers to the applicability to the real-world context and depends, among other things, on a model's predictive power.

Cell lines commonly used in basic and translational research are maintained over many passages and frequently have little resemblance, genetically or functionally, to the tumours from which they originated. Cell line-derived animal models lack the complex contribution of the human stromal and immune compartments of the tumour microenvironment (TME) as well as intra-tumoural clonal heterogeneity [14]. There is now good evidence highlighting the importance of these factors for drug resistance [15-18], tumour invasion [19], metastasis [20, 21] and recurrence [22]. More complex animal models of tumour biology exist including carcinogen-induced models, genetically engineered mouse models (GEMMs), as well as patient-derived xenograft (PDX) and humanized mouse models. Each of these has different strengths and limitations for a given research question and this has been reviewed extensively elsewhere [23, 24].

PDX mouse models, whereby tumour from individual patients is grafted into an immune-deficient animal, stand out amongst these advanced platforms as most accurately resembling the human tumour counterpart genetically, and in many respects functionally [25-27]. PDXs have also been shown in numerous studies to maintain intra-tumoural clonal heterogeneity [28-30] and to most accurately reflect drug efficacies in the clinical setting [7, 31]. There are variations in methodology of grafting and of host mouse strain that can influence engraftment rate, metastatic potential, and attrition of stromal and immune components of the TME.

We hypothesize that PDX models of CRC can be assessed for internal and external validity by characterizing the various models, describing the range of translational applications published to date, and by assessing future 
potential opportunities PDX present for CRC research.

\section{RESULTS}

The systematic review process was conducted according to the PRISMA framework [32] (Figure 1) and considering SYRCLE [33] guidelines. From a search of Ovid MEDLINE and Embase databases, 377 unique records were identified. 316 records were excluded after screening the title and/or abstract on the basis of relevance (most commonly due to the use of a cell line-derived xenograft or alternate tumour type), and not fulfilling the requirement of being a primary research article. There was one study published in two different journals. The reference lists of the remaining 61 records were screened to identify a further 32 records, resulting in 93 full-text articles assessed for eligibility. Of these, 64 were excluded, most commonly on the basis that no validation of the PDX was performed. This left 29 articles for qualitative analysis. Amongst these, 13 articles described model validation and these were the subject of the systematic review. The remaining 16 articles referenced some of these 13 studies as a subsequent publication from that research collaboration. The details of the core 13 articles are outlined in Table 1 . The other 16 secondary studies were considered only in terms of the application of the model to minimise selection bias.

\section{Study characteristics}

Significant heterogeneity existed between studies making a collated analysis difficult (Table 1). There was a steady increase in the number of publications over time, with half of the studies published since 2012 (Figure 2 ). The median number of patient tumours successfully engrafted was 27 (range 1 - 97). Studies either engrafted a combination of primary and metastatic specimens $(n=$ $8)$, all primary CRC specimens $(n=3)$ or all metastatic

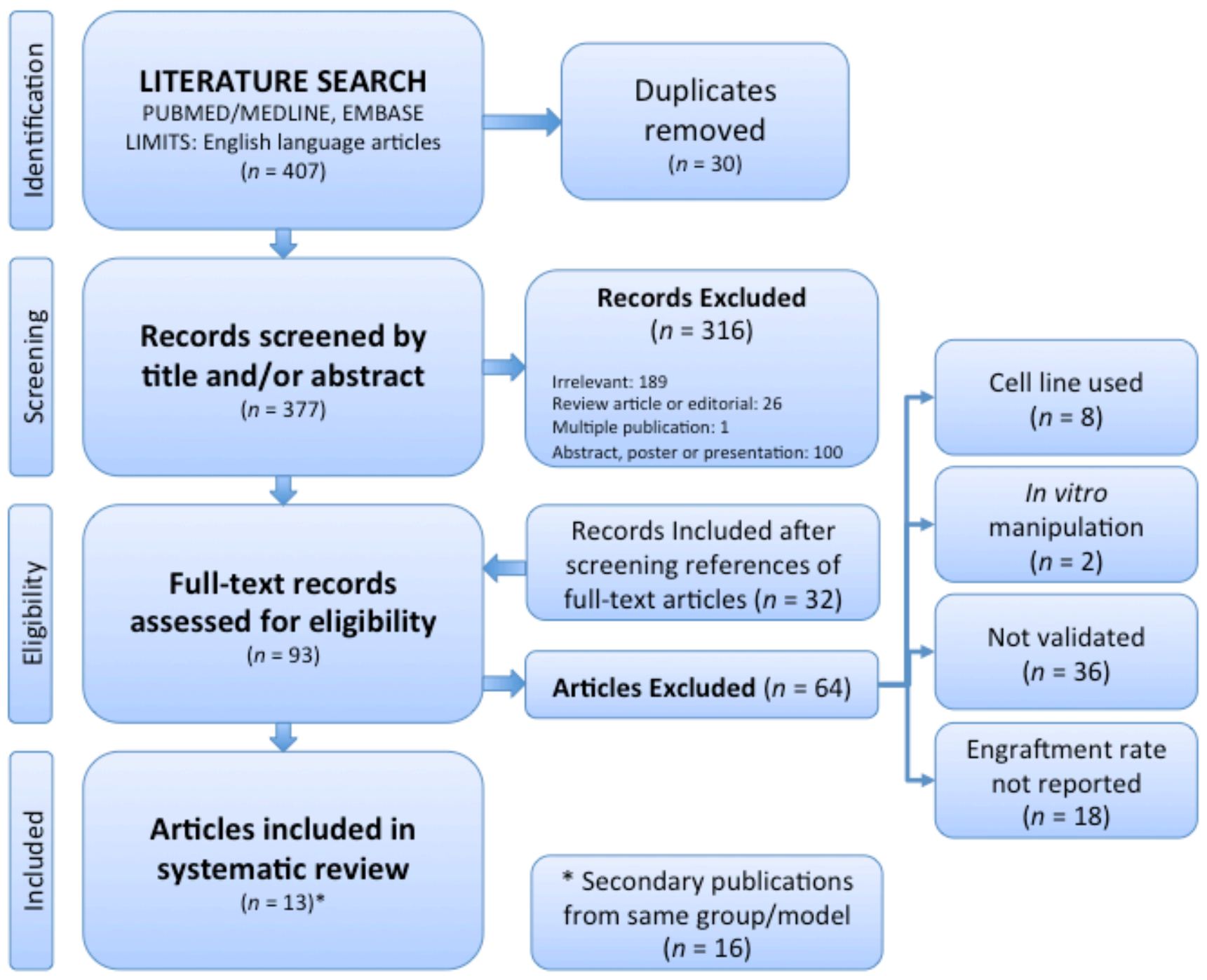

Figure 1: PRISMA Flow Chart. 
CRC specimens $(n=2)$. Studies validated the animal models across a variety of different passages. Julien et. al. [34] used 10 passages but most studies were within 5 or less passages (data not shown). This is consistent with the PDX literature involving other tumour types showing that xenografts are able to maintain a high level of genetic fidelity for at least 5 passages [7, 35].

\section{Xenografting methodology}

Xenografting methodology was highly variable across the studies as noted in Table 1. Athymic nude (nu/ nu) and NOD/SCID (NOD.CB17-Prkdc scid/J or NOD. $\mathrm{CB} 17-\mathrm{Prkdc} \mathrm{c}^{\text {scid }} / \mathrm{NcrCrl}$ ) mice were equally the most frequently used hosts $(n=5)$, with BALB/c nude (C.Cg/ AnNTac-Foxn $1^{n u}$ NE9) mice being the third most common $(n=2)$. SCID-beige (C.B-17/IcrHsd-Prkcd ${ }^{\text {scid }}$ Lyst $\left.^{\text {tg }}\right)$ and

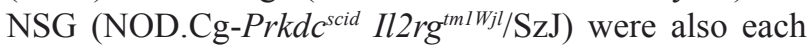
used in two separate studies. Almost all the studies exclusively implanted the grafts within a heterotopic subcutaneous or subrenal pocket $(n=11)$. Four studies engrafted a single cell suspension of enzymatically disassociated patient tumour, but only two of these quantified the number of cells engrafted. The remaining studies used whole tumour fragments. Some studies used multiple fragments per mouse, across a wide range of tumour graft sizes $\left(1-50 \mathrm{~mm}^{3}\right)$, however other studies did not specify. Similarly, a wide range was observed (2-20 mice) for the number of mice engrafted in the first (P1) generation, and some studies did not specify. Only two studies adopted an orthotopic method. Puig et. al. [36] enzymatically digested the tumour specimen into a single cell suspension and then injected a known number of cells into the caecal wall. In contrast, Julien et. al. (2012) sutured a portion of the tumour specimen to the serosa of traumatised murine caecal wall.

\section{Engraftment rates in PDX of CRC are high}

Engraftment rates were described differently across studies with some reporting the relative number of successful human-to-mouse passages while others reported the relative number of successful passages overall. The median overall engraftment rate was $70 \%$ (interquartile range $17 \%$ ). Overall, the rates are significantly higher than PDX models using other primary tumour streams such as

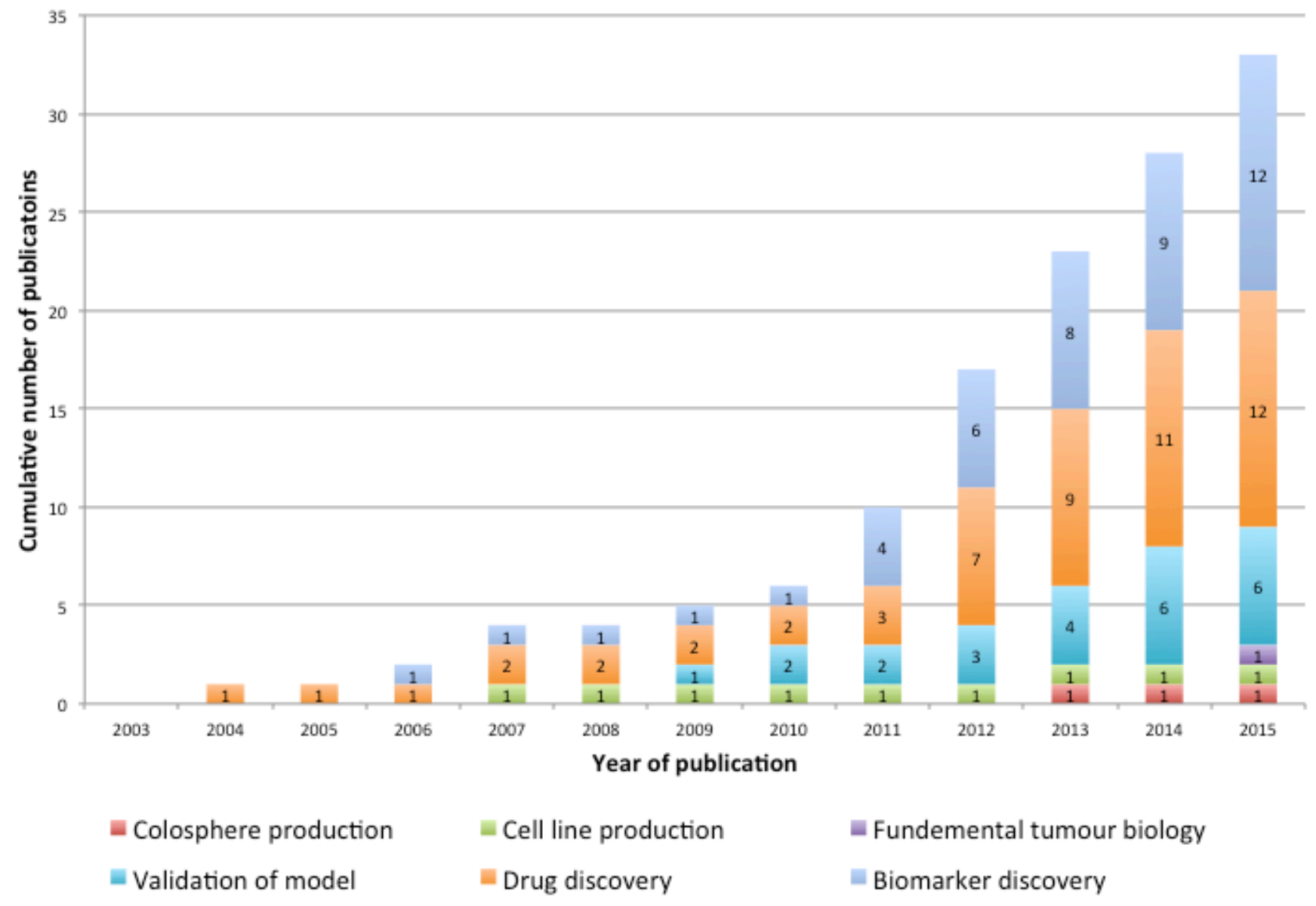

Figure 2: PDX Models of CRC; cumulative number of publications by application and by year of publication. 
Table 2: Validation methods and parameters used to demonstrate PDXs resemble their donor patient tumours

\begin{tabular}{|c|c|c|c|c|c|c|c|c|}
\hline \multirow[b]{2}{*}{ First Author } & \multirow[b]{2}{*}{ Year } & \multicolumn{7}{|c|}{ Validation Method } \\
\hline & & Histology & $\begin{array}{l}\text { Driver Gene } \\
\text { Mutations }\end{array}$ & Gene Expression & $\begin{array}{c}\text { Copy } \\
\text { number } \\
\text { Variation }\end{array}$ & Proteomics & Immunohistochemistry & Other \\
\hline Fichtner[61] & 2004 & Yes & $K R A S$ & ND & ND & & $\begin{array}{c}\text { EpCAM , CEA, p53, Ki- } \\
\text { 67, Topoisomerase Ia } \\
\text { and IIa }\end{array}$ & \\
\hline $\begin{array}{l}\text { Dangles- } \\
\text { Marie[44] }\end{array}$ & 2007 & Yes & ND & qRT-PCR & ND & & & \\
\hline Mischek[67] & 2009 & Yes & ND & $\begin{array}{c}\text { TaqMan low } \\
\text { density expression } \\
\text { array including } \\
\text { Bcl-2, cyclin D1, } \\
\text { CDC25B, CDK } \\
\text { inhibitor 1B, Erb- } \\
\text { b2, K-ras, Met and } \\
\text { Myc, EGFR, } \\
\text { CTNNB1 }\end{array}$ & ND & & CEA, CK8/18, CK20 & \\
\hline $\begin{array}{l}\text { Linnebacher }[4 \\
6]\end{array}$ & 2010 & Yes & ND & ND & ND & & & MSI status \\
\hline Bertotti[47] & 2011 & Yes & $\begin{array}{c}\text { KRAS, NRAS, } \\
\text { BRAF, PIK3CA, } \\
\text { HER2 }\end{array}$ & ND & Yes & & & \\
\hline $\operatorname{Jin}[48]$ & 2011 & Yes & $\begin{array}{c}\text { KRAS, BRAF, } \\
\text { EGFR, and } \\
\text { PIK3CA }\end{array}$ & $\begin{array}{l}\text { Affymetrix } \\
\text { GeneChip } \\
\text { Microarray }\end{array}$ & ND & $\begin{array}{l}\text { Akt, pAkt, ERK, } \\
\text { pERK, MAPK, } \\
\text { pMAPK, mTOR, } \\
\text { mTOR, EGFR, } \\
\text { VEGF, Caspase-3, } \\
\text { PCNA, GAPDH }\end{array}$ & $\begin{array}{l}\text { CK-20, CDX-2, VEGF, } \\
\text { EGFR }\end{array}$ & \\
\hline $\operatorname{Kim}[50]$ & 2012 & Yes & $\begin{array}{c}\text { TP53, APC; } \\
\text { AKT1, BRAF, } \\
\text { FBXW7, CTNNB1, } \\
\text { KRAS, PIK3CA, } \\
\text { EGFR, KDR, } \\
\text { FCGR } 2 A, \\
\text { FCGR } 3 A, E R C C I\end{array}$ & $\begin{array}{l}\text { Affymetrix } \\
\text { GeneChip } \\
\text { Microarray }\end{array}$ & Yes & & & MSI status \\
\hline Julien[34] & 2012 & Yes & ND & $\begin{array}{l}\text { Affymetrix } \\
\text { GeneChip } \\
\text { Microarray }\end{array}$ & ND & & & \\
\hline Monsma[40] & 2012 & Yes & $K R A S, P I K 3 C A$ & $\begin{array}{l}\text { Affymetrix } \\
\text { GeneChip } \\
\text { Microarray }\end{array}$ & ND & & & \\
\hline Puig[36] & 2013 & Yes & $\begin{array}{l}B R A F, K R A S, \\
A P C, P I K 3 C A\end{array}$ & Nanostring & ND & & $\begin{array}{c}\text { b-catenin, caspase-3, } \\
\text { chromogrannin A, } \\
\text { CK20, EpCAM, Ki67, } \\
\text { MUC2, Villin-1 }\end{array}$ & $\begin{array}{l}\text { Some correlation } \\
\text { of } \\
\text { clinicopathalogical } \\
\text { characteristics }\end{array}$ \\
\hline Chou[43] & 2013 & Yes & $A P C$ & $\begin{array}{c}\text { RNA-seq } \\
\text { including PROM1, } \\
\text { ALCAM, CD44, } \\
\text { CD24 }\end{array}$ & ND & & $\begin{array}{l}\text { HLA-1, CEA, CK20, } \\
\text { Ki-67, CD31, EPCAM, } \\
\text { E-Cadherin, PD1, } \\
\text { vimentin, fibronectin, } \\
\text { CD4, CD8, CD3 }\end{array}$ & \\
\hline Lee[42] & 2014 & Yes & $\begin{array}{c}\text { TP53, KRAS, } \\
\text { PIK3CA, APC, } \\
\text { FBXW7, STK11, } \\
\text { MET, SMARCB1, } \\
\text { ATM, MLH1, } \\
\text { PTEN, ERBB2 }\end{array}$ & ND & ND & & & \\
\hline Cho[49] & 2014 & Yes & $\begin{array}{c}B R A F, K R A S, \\
P I K 3 C A, T P 53 \\
A P C\end{array}$ & $\begin{array}{l}\text { Agilent } 60 \mathrm{~K} \\
\text { expression } \\
\text { microarray }\end{array}$ & ND & & CK20, CK7, CEA & $\begin{array}{l}\text { Short tandem } \\
\text { repeat analysis, } \\
\text { MSI status }\end{array}$ \\
\hline
\end{tabular}

breast [37], prostate [38], bladder [39], pancreatic [40] or melanoma [41]. Lee et. al. [42] published an engraftment rate of $100 \%$ in both the first and second generation of mice, which is well above that described in the CRC PDX literature. However, this study involved small numbers of patients $(n=10)$ and only relatively advanced tumours were selected for grafting $(40 \%$ of patients were Stage IV and $60 \%$ were Stage III, $80 \%$ showed lymphovascular invasion and only $10 \%$ were well-differentiated).

PDX models using a NOD/SCID strain had the highest engraftment rate, followed by $\mathrm{BALB} / \mathrm{c}$ nude and $\mathrm{nu} / \mathrm{nu}$, with median rates of $78 \%(n=4), 67 \%(n=2)$ and $63 \%(n=5)$, respectively. There was a statistically significant difference in engraftment amongst NOD/ SCID versus nu/nu strains $(p<0.0001$, OR 3.3, 95\% $\mathrm{CI}=2.08$ - 5.33). Of only four studies [34, 36, 43, 44] that reported engraftment rate according to primary versus metastatic tumour graft, there was no statistically significant difference in the individual studies or the pooled data $(p=0.37$, OR $0.74,95 \% \mathrm{CI}=0.39-1.4)$. This contrasts with observations elsewhere in the literature that metastases have an enhanced ability to successfully 
engraft [41, 45]. Puig et. al. [36] did however, note that metastasis-derived grafts trended towards a shorter (mean $\pm \mathrm{SD}$ ) latency time than primary tumour grafts (46.6 \pm 21.7 versus $68 \pm 34$ days, respectively), and that nodenegative or well differentiated primary tumours had a significantly lower engraftment rate compared with more biologically aggressive primary tumours. The preparation of the tumour graft prior to implantation may also be important although no studies specifically examined this. Interestingly, Linnebacher et. al. [46] found no statistically significant difference in engraftment rates between fresh and cryopreserved grafts (74\% versus $71 \%)$.

\section{Orthotopic PDX of CRC can develop endogenous distant metastases}

The only two CRC PDX models that developed endogenous metastases used an orthotopic method of engraftment (i.e. the tumour was implanted in or near the site of the original source of the tumour rather than in a metastatic site). This is consistent with observations from other tumour types where subcutaneous engraftments almost never produce metastasis [23]. In one of the included studies, 13 of 66 orthotopically engrafted tumours (19.7\%) generated distant metastases (to liver and lung) as detected by positron emission topography (PET) and confirmed histologically ex vivo [36]. This excludes peritoneal carcinomatosis that conceivably could be deposited during orthotopic engraftment. Interestingly, the only orthotopically implanted liver metastasis-derived graft did not result in metastases within the model. In another study there was no difference in metastasis rate noted at necropsy (32\% overall) in orthotopic PDXs derived from primary versus metastatic tumours [34]. Both of these studies observed the orthotopic xenografts for up to 90 days.

\section{PDX models of CRC maintain a high degree of microscopic, genetic and functional fidelity to the original donor tumour}

In addition to hematoxylin and eosin staining and histological comparison to the original tumour, the included studies validated the various models by examining preservation of key driver gene mutations, most commonly $K R A S, B R A F$ and PIK3CA (9 studies); gene expression ( 8 studies); copy number variations (2 studies) and protein expression (predominantly via immunohistochemistry). Three studies looked at preservation of microstatellite instability status. These comparative parameters are outlined in Table 2.

All studies showed a strong preservation of tumour and stromal architecture and histological differentiation. Furthermore, there was evidence that engrafted tumour cells maintained pleuripotency by differentiating into appropriate proportions of mucinosecretory, absorptive and enteroendocrine cells [36], as well as maintained their histopathological subtypes [34]. Protein expression was similar between matched patient tumour and PDX tumour pairs when examined by western blot or immunohistochemistry.

Correlation between key genetic lesions in patient tumours compared to PDX tumours was reported inconsistently. Generally, key genetic lesions were well preserved in PDXs and were noted to occur at similar frequencies to that published in the literature [34]. Puig et al. [36] found 100\% concordance amongst 12 matched patient-PDX tumour pairs whereas Lee et. al. [42] found only $80 \%$ concordance across 10 pairs, with two PDXs developing a new mutation in both PIK3CA and FBWX7. However, Bertolli et al. [47] noted that wild-type cases persisted unaltered through serial passages and further validated the genomic stability of their PDX model by showing that copy number variation (CNV) between matched pairs was preserved amongst early passages. Similarly, Julien et al. [34] found high genomic stability in CNV for up to 10 passages amongst $90 \%$ of cases (34/38 matched pairs). The remaining four matched pairs had very high CNV and thus considered highly genetically unstable, or very low CNV that reduces the accuracy of the CNV assay.

With regard to maintenance of gene expression, correlation between early passage PDXs and original patient tumours was high overall, and in some studies very high with Pearson correlation coefficients (r) ranging between $r=0.86$ and $r=0.99$ [40, 43, 44, 48]. However, these data are based on limited subsets of successful engraftments and many studies reported these observations differently. Some describe close clustering patterns on gene arrays but methods of measuring clustering are not consistently reported [34, 49, 50]. Puig et. al. [36] noted perfect gene expression clustering of mucinous adenocarcinoma PDX subtypes compared with non-mucinous adenocarcinoma subtypes. In contrast, Dangles-Marie et. al. found that only 2 of 7 paired PDXs and patient tumours had a high gene expression correlation $(\mathrm{r}=0.912$ and 0.815$)$ [44]. This study used real-time PCR to examine a focused set of 69 genes in one pair and only 17 genes in the remaining 6 pairs, which might explain the different results.

Several studies noted that, of the genes that were different between paired PDXs and patient tumours, many were down regulated and were associated with stroma or the immune system $[34,43,47]$. Furthermore it has been observed that human stroma is often rapidly replaced by murine stroma across the first few passages [51]. Some authors suggest this difference in gene expression is due to the inability of human molecular probes to detect murine stromal analogues and the fact that the animal host is immunodeficient. Consistent with this theory is the observation that there is greater correlation for 
global gene expression patterns between subsequent PDX generations than there is between patient tumours and the first generation PDX [34, 43].

From a functional standpoint, orthotopic PDX models stood out as being able to generate 'primary tumours' and distant lung and liver metastases at similar rates observed in patients [34, 36]. Furthermore, three of the studies specifically examined PDX response rates to cetuximab [34, 47] and systemic chemotherapy [34, 50] and found they reflected clinical response rates. Importantly, they also successfully identified cetuximabresistant $K R A S$ mutant and wild type $K R A S /$ mutant $B R A F$ or $P I 3 K$ subtypes.

\section{Validated PDX models of CRC are being used as platforms for multiple applications}

Of the 13 included articles in the present review which described a validated PDX model of CRC, a further 16 articles were subsequently published using these models and so these were also considered when evaluating current applications of PDX models in CRC research. Four articles used their model in multiple applications, with 33 total applications across 29 studies. These are illustrated by year of publication in Figure 2 .

Applications of PDX models in CRC research ranged across six broad domains, including biomarker discovery [19, 34, 47, 52-60], drug discovery [36, 44, 48, 50, 60-66], PDX model validation alone [40, 42, 43, $46,49,67]$, research pertaining to fundamental tumour biology [19], cell line production [44] and colosphere production [68]. Biomarker discovery and drug discovery (12 studies each) were the most frequent applications, representing $70 \%$ of the published studies. The median year of publication was 2012, where there was a particular increase in the number of published studies relating to drug discovery.

\section{Potential sources of bias}

Due to the large variation in methodology and reporting across studies no quantitative analysis of bias could be performed. However, a number of common issues appeared that could serve as potential sources of bias. Overall, there was poor compliance with ARRIVE guidelines with all studies failing to address at least one ARRIVE item [12].

Across most studies, selection bias was likely high. Dangles-Marie et al. [44] only used samples taken from patients with advanced cancers undergoing palliative resections. Only four of 13 included studies gave a comprehensive description of the clinico-pathological characteristics of the patient tumours [34, 36, 42, 47]. All other studies failed to adequately describe how patients were selected for xenografting or their clinical details including whether they had been exposed to prior chemotherapy. Two studies completely changed their methodology during the study by altering the strain of mouse used $[42,69]$.

Seven of the studies involved a treatment cohort of PDX mice [34, 36, 44, 47, 48, 50, 61]. However, only two $[47,48]$ reported randomisation of mice to treatment groups although there was not detailed description of the randomisation process. The remaining studies did not describe the treatment allocation process and no study reported power calculations or methods of blinding in reporting results.

Reporting bias was also high in a number of studies, particularly in relation to engraftment rate where it was often unclear if engraftment success referred to tumour growth per mouse engrafted or per patient tumour. Reporting of gene mutation and gene expression analysis was also highly variable, with only one study reporting precisely at which passage the analysis was performed [42], and four studies failing to quantitatively present the results $[47,49,67,69]$. Only two studies investigated why some tumours failed to engraft. Bertolli et al. [47] noted that these failures tended not to have mutations in $K R A S$, $N R A S, B R A F$ or PIK3CA. In contrast, Chou et al. [43] could not identify any clinico-pathological characteristics associated with failure to engraft.

\section{DISCUSSION}

Animal models in the study of cancer have been the cornerstones of pre-clinical research for the last 50 years. However, there are limitations with regard to external validity particularly in relation to the critical role that intra-tumoural heterogeneity and the TME have in cancer growth, metastasis and drug resistance [20, 70]. Not surprisingly there are relatively few translational success stories from bench to bedside. This is also true in colorectal cancer where the mainstay of adjuvant treatment continues to be toxic platinum-based chemotherapy, and where there are limited biomarkers or high impact targeted therapies [71]. This is the first systematic review of PDX models of CRC providing a comprehensive assessment of the PDX platform as a tool for pre-clinical research.

The major criticism of the internal validity of a PDX model is the difficulty in controlling for variables intrinsic to a patient-derived sample such as uncertainty in quantifying the amount of viable tumour being transplanted, intra-tumoural heterogeneity or by some other confounding genetic trait unknown to the investigator at the time of engraftment [27]. This is in addition to other factors such as the various host mouse stains and grafting methodologies used within and across studies, the use of both primary and metastatic samples and the impact of any neo-adjuvant treatment. Whilst this review found that there was a significant difference $(\mathrm{p}<$ 0.0001 , OR $3.3,95 \% \mathrm{CI}=2.08-5.33$ ) in engraftment 
rate amongst NOD/SCID versus nu/nu strains, this result should be considered with a high level of caution, as there was significant heterogeneity in xenografting methodology and variation in reporting of results amongst the included studies. All the above variables could theoretically lead to selection pressure in PDX models resulting in more aggressive tumours being overrepresented in successful PDX engraftments. This would be a source of strong selection bias in the studies reviewed.

While some authors suggest that such non-random selection of tumours or clones that bias engraftment may define a PDX model (by revealing clonal dynamics) rather than limit its usefulness [30], findings from the present review suggest that the risk of selection bias in CRC PDX models may be overstated. Firstly, mice can be reliably engrafted with CRC tumours at rate of $70 \%$ or more, with a full representation of histopathological subtypes and microsatellite instability (MSI) status [34, 69]. Secondly, despite the small study from Lee et al. [42], there was no definitive correlation in this review between engraftment rate and stage or grade of the donor tumour (as a surrogate for 'tumourigenicity'). This contrasts with breast cancer models where triple negative tumours are positively selected during engraftment and passage [37] as well as in non-small cell lung cancer PDX models [45]. Further supporting evidence of the reliability of CRC PDX models is that frequencies of mutant and wild-type driver genes usually mirror those found in the clinical setting, including $K R A S, N R A S, B R A F$ and PIK3CA [36, 47]. Furthermore, those few studies where a new mutations were detected in PDX tumours but not the original patient samples could reflect low-frequency clones that were below the threshold necessary for detection in the original tumour [42, 47, 49]. This conclusion is consistent with other evidence showing that a library of PDX models are able to display the intratumoural heterogeneity of their original patient tumour, both in CRC and breast cancer [28, 29, 72]. If therefore in $\mathrm{CRC}$, the PDX models can be reproducibly engrafted and mimic the spectrum of clinical disease, the effect of selection pressure on internal validity could be regarded as minimal.

External validity of animal models (how well observations in the model translate to clinical practice) relies on adequate representation of the clinical disease. The present review found that PDX models of CRC maintain a high level of genomic, transcriptional and phenotypic fidelity to the original patient tumour. Preservation of mutations in key driver genes between matched patient and PDX tumours ranged between 80 $100 \%$. Furthermore, genetic stability was further shown by maintenance of CNV amongst at least $90 \%$ of cases for up to 10 passages. Others have observed the pattern of chromosomal instability in CRC PDXs to be maintained over 14 passages [29]. In this review, all but one study (which only examined a small number of genes) found that gene expression patterns were well preserved amongst paired patient and xenograft tumours. Whilst there is no clear 'cuff-off', given the varying methodologies and passages used to assess genetic fidelity in this review, as well as the varied degree of stability across passages in other tumour streams [7], the fidelity of CRC PDXs in late passages must be accepted with caution. Nonetheless by the same measure, the breadth of methodologies used clearly demonstrate there is lack of genetic drift across early-mid passages, which further corroborates the internal validity of PDX models in CRC research. Overall, the conservation of histological subtypes, MSI status, key driver mutations and gene expression from patient tumours to their corresponding PDXs demonstrate that, at least in CRC, PDX models faithfully recapitulate a full spectrum of clinical disease.

In several studies, the differences in gene expression that were observed between matched patient and PDX tumours were found to correspond to down-regulated human stromal and immune-related genes. This is not unexpected as it has been shown that co-engrafted human tumour stroma is usually replaced by murine stroma in the immunodeficient host by the third passage [19, 73]. Nonetheless, at the microscopic level, all included studies demonstrated that the histology of the original tumour was maintained. It is unclear as to what degree differences in receptor-ligand homology as co-engrafted TME is replaced by murine stroma may affect the external validity of PDX models in this regard. Having said that, a recent study used this feature of PDX models to show that an engrafted CRC induced a gene expression signature in murine fibroblasts that correlated with the original patient cancer-associated fibroblasts (CAFs), as well as independently predicted clinical outcomes [19]. Clearly, the immune-deficient status of the murine hosts required to accept human tumour samples without rejection is a major drawback in investigating the role of the immune system in tumourigenesis. This issue will need to be addressed in future PDX research.

Despite the drawback of variable stromal preservation and absence of a competent immune system, repeatedly PDX models in CRC have demonstrated excellent predictive power, which can be considered a measure of external validity. Of the included studies that examined PDX response rates to conventional therapies, there was a close correlation with those found in the clinical setting [34, 47, 50]. Furthermore, Julien et al. [34] found a positive correlation between poor xenograft response to cetuximab and $K R A S, B R A F$ or $P I K 3 C A$ mutational status, which is also used to predict patient response. Kim et al. [50] were able to show a statistically significant correlation between an oxaliplatin response gene expression signature in a panel of CRC PDX models and an independent clinical cohort. Importantly, all these studies used clinically relevant doses in the PDX. Finally, the observation that orthotopic CRC PDX models generate 'primary tumours' and distant lung and liver metastases at 
similar rates observed to that in patients $[34,36]$ may be in part due to the fact that orthotopic models more closely resemble the native TME and hence may improve external validity. This advantage is partly offset by the difficultly in accurately measuring orthotopically engrafted tumours, even with sophisticated imaging systems. By contrast, subcutaneous sites of engraftment are straightforward to measure tumour growth, but almost never generate metastases. Together these studies show the applicability of well-designed PDX platforms to the clinical context of CRC.

This review found an increasing number of publications and an expanding range of applications for PDX models in CRC in the published literature. Even within the strict inclusion criteria of this systematic review, publications using PDX models of CRC have doubled in the last three years (Figure 2). The majority of these studies pertained to either drug or biomarker discovery, with cetuximab the most frequently investigated drug, amongst other targeted agents. Using PDX models as an intermediary to generating CRC cell-lines or colospheres is not common despite this technique having far higher success rates than generating primary cell cultures directly from tumours. Interestingly, there has also been interest in using the PDX model to address fundamental CRC biology research questions. One study used a NOD/ SCID PDX model to show that a poor prognosis stem/ serrated/mesenchymal CRC subtype was characterised by a CAF specific gene signature, challenging the paradigm that mesenchymal and stemness traits are attributed to epithelial tumour cells [19].

There were several limitations of the present review due to the high degree of heterogeneity between included studies. A number of different engraftment methods, mouse strains, experimental endpoints and reporting standards were used which precluded the ability to perform a meta-analysis or funnel plot analysis of bias. None of the studies reported results according to ARRIVE guidelines and all the studies were at high risk of bias. This is an observation that is, unfortunately endemic amongst pre-clinical animal research $[74,75]$.

\section{FUTURE DIRECTIONS}

As demand for improved translational outcomes in CRC research increases the use of advanced PDX models has expanded as demonstrated in this review. Accordingly, there is a need to ratify uniform reporting standards, such as the ARRIVE guidelines, in order to make pre-clinical animal studies more transparent and suitable for more powerful meta-analyses. This would help ensure that preclinical animal studies are upheld to the same standards as their clinical counterparts.

The complexity of in vivo models is rapidly advancing which may overcome some of the current limitations of PDXs. Newer mouse strains such as the NSG and NOG (NOD/Shi-Prkde ${ }^{\text {scid }}$ Il2 $\mathrm{rc}^{\mathrm{tm} \text { ISug} / J i c) ~ s t r a i n s ~ h a v e ~}$ improved engraftment rates compared with other animals which may reduce selection bias [76]. Furthermore, using a so-called 'omental' site of engraftment for both nonsmall cell lung cancer and ovarian cancer in an NSG host has been shown to maintain and expand functional coengrafted CAFs and tumour-infiltrating lymphocytes [77, 78]. Such strategies of better recapitulating the TME in animal models should hopefully increase their external validity.

The next tipping point in PDX technology will undoubtedly be widespread access to humanised PDX models (huPDX) which have been outlined elsewhere [76]. In short, huPDX create either genetic or cellular chimaeras that combine the advantages of a humanderived tumour with a variably intact immune system. Such a CRC huPDX would be especially relevant due to high intra-tumoural heterogeneity in colorectal cancer, variable immunogenicity (such as microsatellite stable vs. unstable) and other clinical evidence of importance of immune response [79]. Currently available huPDX models are prohibitively difficult to establish or encounter issues with HLA-mismatch and tumour rejection or graft-versus host disease. At present, work is underway to establish transgenic NSG mice that express human HLA-I/II and lack mouse MHC-I/II or express human growth factors and cytokines [24] which may facilitate 'off the shelf' huPDX. It therefore is no surprise that PDX 'banks' are being established in both America and across Europe, asserting the future of PDX models in basic science and pre-clinical CRC research.

\section{MATERIALS AND METHODS}

The study protocol for this systematic review followed the PRISMA (Preferred Reporting Items for Systematic Reviews and Meta-Analyses) checklist [32] and used the SYRCLE (Systematic Review Centre for Laboratory animal Experimentation) guidelines for relevant additions [33].

\section{Search strategy}

A search of the Ovid MEDLINE and Embase databases was performed up to July 2015 to identify studies involving PDX models of CRC. The search was limited to English language papers. Both medical subject heading and free text searching were used to increase the sensitivity of the search. The search terms included in the Ovid MEDLINE string and the Embase string are shown in Supplementary Appendix S1 and Supplementary Appendix S2, respectively.

Papers were first screened on title and abstract for 
relevance and eligibility before the full text of remaining papers were screened for eligibility. Additional papers were identified by manually screening the references of any included study.

\section{Inclusion criteria}

Included papers had to be English language primary research articles that used a primary or metastatic colorectal PDX model without any intervening in vitro manipulation. Any method of engraftment could be included, however papers were not included if xenografts had undergone significant in vitro manipulation (such as cell culture) prior to engraftment. Papers were only included if the engraftment rate was explicitly stated, as the absence of this information might contribute to selection bias in the model or data. Successful engraftment was broadly considered as any xenograft of sufficient volume for downstream ex vivo or in vivo study. Lastly, the models described must have undergone a process of validation in addition to comparative haematoxylin and eosin histology in order to sufficiently explore genetic and or phenotypic differences between patient tumour and their corresponding xenografts. Reviews and editorial articles were excluded from this review.

\section{Data extraction}

Each included paper was manually searched for parameters including host mouse strain, engraftment rate, site of engraftment (heterotopic or orthotopic), development of metastases in the model and primary or metastatic donor tumour source. Validation methods including preservation of histology, driver gene mutations, gene expression, copy number variation, immunohistochemistry, proteomics and others were annotated. Where a study did not directly validate the model in the manuscript but instead referenced a previous published validation study, these were grouped accordingly.

\section{Statistical analysis}

Statistical analysis was performed by the 2-tailed $\chi 2$ test using Microsoft Excel for Mac 2011 (version 14.5.9) and Prism 6 for Mac OSX (version 6.0f). For all tests, the level of statistical significance was set at $P<0.05$.

\section{CONFLICTS OF INTEREST}

None to disclose.

\section{FUNDING}

Kai Brown was supported in this work by the Australian and New Zealand Hepatic, Pancreatic and Biliary Association Research Scholarship.

\section{REFERENCES}

1. Australian Institute of Health and Welfare. Cancer in Australia 2010: an overview. Canberra; 2010 Dec. Report No.: Cancer series no. 60. Available from http://www.aihw. gov.au/publication-detail/?id=6442472459.

2. GLOBOCAN, International Agency for Research on Cancer. Colorectal Cancer Estimated Incidence, Mortality and Prevalence Worldwide in 2012. 2012 [cited 2014 Sep 21]. Available 2014 Sep 21, from http://globocan.iarc.fr/ Pages/fact sheets_cancer.aspx.

3. Renouf DJ, Woods R, Speers C, Hay J, Phang PT, Fitzgerald C, Kennecke H. Improvements in 5-year outcomes of stage II/III rectal cancer relative to colon cancer. Am J Clin Oncol. 2013; 36: 558-64. doi: 10.1097/ COC.0b013e318256f5dc.

4. Sargent D, Sobrero A, Grothey A, O'Connell MJ, Buyse M, Andre T, Zheng Y, Green E, Labianca R, O'Callaghan C, Seitz JF, Francini G, Haller D, et al. Evidence for cure by adjuvant therapy in colon cancer: observations based on individual patient data from 20,898 patients on 18 randomized trials. J Clin Oncol. 2009; 27: 872-7. doi: 10.1200/JCO.2008.19.5362.

5. Brenner H, Kloor M, Pox CP. Colorectal cancer. Lancet. 2014; 383: 1490-502. doi: 10.1016/S0140-6736(13)616499.

6. DiMasi JA, Reichert JM, Feldman L, Malins A. Clinical approval success rates for investigational cancer drugs. Clin Pharmacol Ther. 2013; 94: 329-35. doi: 10.1038/ clpt.2013.117.

7. Tentler JJ, Tan AC, Weekes CD, Jimeno A, Leong S, Pitts TM, Arcaroli JJ, Messersmith WA, Eckhardt SG. Patientderived tumour xenografts as models for oncology drug development. Nat Rev Clin Oncol. 2012; 9: 338-50. doi: 10.1038/nrclinonc.2012.61.

8. Sharpless NE, Sharpless NE, DePinho RA, Depinho RA. The mighty mouse: genetically engineered mouse models in cancer drug development. Nat Rev Drug Discov. 2006; 5: 741-54. doi: 10.1038/nrd2110.

9. Khaled WT, Liu P. Cancer mouse models: past, present and future. Semin Cell Dev Biol. 2014; 27: 54-60. doi: 10.1016/j.semcdb.2014.04.003.

10. Sams-Dodd F. Strategies to optimize the validity of disease models in the drug discovery process. Drug Discovery Today. 2006; 11: 355-63. doi: 10.1016/j. drudis.2006.02.005.

11. Denayer T, Stöhr T, Van Roy M. Animal models in translational medicine: Validation and prediction. New 
Horizons in Translational Medicine. 2014; 2: 5-11. doi: 10.1016/j.nhtm.2014.08.001.

12. Kilkenny C, Browne WJ, Cuthill IC, Emerson M, Altman DG. Improving bioscience research reporting: the ARRIVE guidelines for reporting animal research. PLoS Biol. 2010; 8: e1000412. doi: 10.1371/journal.pbio.1000412.

13. Sena ES, Currie GL, McCann SK, Macleod MR, Howells DW. Systematic reviews and meta-analysis of preclinical studies: why perform them and how to appraise them critically. J Cereb Blood Flow Metab. 2014; 34: 737-42. doi: $10.1038 /$ jcbfm.2014.28.

14. Tabassum DP, Polyak K. Tumorigenesis: it takes a village. Nat Rev Cancer. 2015; 15: 1-11. doi: 10.1038/nrc3971.

15. Junttila MR, de Sauvage FJ. Influence of tumour microenvironment heterogeneity on therapeutic response. Nature. 2013; 501: 346-54. doi: 10.1038/nature12626.

16. Klemm F, Joyce JA. Microenvironmental regulation of therapeutic response in cancer. Trends Cell Biol. 2015; 25: 198-213. doi: 10.1016/j.tcb.2014.11.006.

17. Coffelt SB, de Visser KE. Immune-mediated mechanisms influencing the efficacy of anticancer therapies. Trends Immunol. 2015; 36: 198-216. doi: 10.1016/j.it.2015.02.006.

18. McMillin DW, Negri JM, Mitsiades CS. The role of tumour-stromal interactions in modifying drug response: challenges and opportunities. Nat Rev Drug Discov. 2013; 12: 1-12. doi: 10.1038/nrd3870.

19. Isella C, Terrasi A, Bellomo SE, Petti C, Galatola G, Muratore A, Mellano A, Senetta R, Cassenti A, Sonetto C, Inghirami G, Trusolino L, Fekete Z, et al. Stromal contribution to the colorectal cancer transcriptome. Nat Genet. 2015; 47: 312-9. doi: 10.1038/ng.3224.

20. Quail DF, Joyce JA. Microenvironmental regulation of tumor progression and metastasis. Nat Med. 2013; 19: 1423-37. doi: 10.1038/nm.3394.

21. Kitamura T, Qian B-Z, Pollard JW. Immune cell promotion of metastasis. Nat Rev Immunol. 2015; 15: 73-86. doi: 10.1038/nri3789.

22. Alderton GK. Tumour microenvironment: Driving relapse. Nat Rev Cancer. 2015; 15: 195-5. doi: 10.1038/nrc3935.

23. Day C-P, Merlino G, Van Dyke T. Preclinical Mouse Cancer Models: A Maze of Opportunities and Challenges. Cell. 2015; 163: 39-53. doi: 10.1016/j.cell.2015.08.068.

24. Shultz LD, Goodwin N, Ishikawa F, Hosur V, Lyons BL, Greiner DL. Human cancer growth and therapy in immunodeficient mouse models. Cold Spring Harb Protoc. 2014; 2014: 694-708. doi: 10.1101/pdb.top073585.

25. Fichtner I, Rolff J, Soong R, Hoffmann J, Hammer S, Sommer A, Becker M, Merk J. Establishment of patientderived non-small cell lung cancer xenografts as models for the identification of predictive biomarkers. Clin Cancer Res. 2008; 14: 6456-68. doi: 10.1158/1078-0432.CCR-08-0138.

26. Rubio-Viqueira B, Jimeno A, Cusatis G, Zhang X, Iacobuzio-Donahue C, Karikari C, Shi C, Danenberg K, Danenberg PV, Kuramochi H, Tanaka K, Singh S, Salimi-
Moosavi $\mathrm{H}$, et al. An in vivo platform for translational drug development in pancreatic cancer. Clin Cancer Res. 2006; 12: 4652-61. doi: 10.1158/1078-0432.CCR-06-0113.

27. Hidalgo M, Amant F, Biankin AV, Budinská E, Byrne AT, Caldas C, Clarke RB, de Jong S, Jonkers J, Mælandsmo GM, Roman-Roman S, Seoane J, Trusolino L, et al. Patient-derived xenograft models: an emerging platform for translational cancer research. Cancer Discov. 2014; 4: 998-1013. doi: 10.1158/2159-8290.CD-14-0001.

28. Eirew P, Steif A, Khattra J, Ha G, Yap D, Farahani H, Gelmon K, Chia S, Mar C, Wan A, Laks E, Biele J, Shumansky K, et al. Dynamics of genomic clones in breast cancer patient xenografts at single-cell resolution. Nature. 2015; 518: 422-6. doi: 10.1038/nature13952.

29. Guenot D, Guérin E, Aguillon-Romain S, Pencreach E, Schneider A, Neuville A, Chenard M-P, Duluc I, Manoir Du S, Brigand C, Oudet P, Kedinger M, Gaub M-P. Primary tumour genetic alterations and intra-tumoral heterogeneity are maintained in xenografts of human colon cancers showing chromosome instability. J Pathol. 2006; 208: 64352. doi: 10.1002/path.1936.

30. Cassidy JW, Caldas C, Bruna A. Maintaining Tumor Heterogeneity in Patient-Derived Tumor Xenografts. Cancer Res. 2015; 75: 2963-8. doi: 10.1158/0008-5472. CAN-15-0727.

31. Gao H, Korn JM, Ferretti S, Monahan JE, Wang Y, Singh M, Zhang C, Schnell C, Yang G, Zhang Y, Balbin OA, Barbe S, Cai H, et al. High-throughput screening using patient-derived tumor xenografts to predict clinical trial drug response. Nat Med. 2015; 21: 1318-25. doi: 10.1038/ nm.3954.

32. Liberati A, Altman DG, Tetzlaff J, Mulrow C, Gøtzsche PC, Ioannidis JPA, Clarke M, Devereaux PJ, Kleijnen J, Moher D. The PRISMA Statement for Reporting Systematic Reviews and Meta-Analyses of Studies That Evaluate Health Care Interventions: Explanation and Elaboration. PLoS Med. 2009; 6: e1000100-28. doi: 10.1371/journal. pmed.1000100.

33. de Vries RBM, Hooijmans CR, Langendam MW, van Luijk J, Leenaars M, Ritskes-Hoitinga M, Wever KE. A protocol format for the preparation, registration and publication of systematic reviews of animal intervention studies. Evidence-based Preclinical Medicine. 2015; 2: 1-9. doi: 10.1002/ebm2.7.

34. Julien S, Merino-Trigo A, Lacroix L, Pocard M, Goéré D, Mariani P, Landron S, Bigot L, Nemati F, Dartigues P, Weiswald L-B, Lantuas D, Morgand L, et al. Characterization of a large panel of patient-derived tumor xenografts representing the clinical heterogeneity of human colorectal cancer. Clin Cancer Res. 2012; 18: 5314-28. doi: 10.1158/1078-0432.CCR-12-0372.

35. Zhang X, Claerhout S, Prat A, Dobrolecki LE, Petrovic I, Lai Q, Landis MD, Wiechmann L, Schiff R, Giuliano M, Wong H, Fuqua SW, Contreras A, et al. A renewable tissue resource of phenotypically stable, biologically and 
ethnically diverse, patient-derived human breast cancer xenograft models. Cancer Res. 2013; 73: 4885-97. doi: 10.1158/0008-5472.CAN-12-4081.

36. Puig I, Chicote I, Tenbaum SP, Arqués O, Herance JR, Gispert JD, Jimenez J, Landolfi S, Caci K, Allende H, Mendizabal L, Moreno D, Charco R, et al. A personalized preclinical model to evaluate the metastatic potential of patient-derived colon cancer initiating cells. Clin Cancer Res. 2013; 19: 6787-801. doi: 10.1158/1078-0432.CCR12-1740.

37. Marangoni E, Vincent-Salomon A, Auger N, Degeorges A, Assayag F, de Cremoux P, De Plater L, Guyader C, De Pinieux G, Judde J-G, Rebucci M, Tran-Perennou C, SastreGarau X, et al. A new model of patient tumor-derived breast cancer xenografts for preclinical assays. Clin Cancer Res. 2007; 13: 3989-98. doi: 10.1158/1078-0432.CCR-07-0078.

38. van Weerden WM, Bangma C, de Wit R. Human xenograft models as useful tools to assess the potential of novel therapeutics in prostate cancer. Br J Cancer. 2009; 100: 13-8. doi: 10.1038/sj.bjc.6604822.

39. Bernardo C, Costa C, Sousa N, Amado F, Santos L. Patient-derived bladder cancer xenografts: a systematic review. Translational Research. 2015; : 1-8. doi: 10.1016/j. trs1.2015.02.001.

40. Monsma DJ, Monks NR, Cherba DM, Dylewski D, Eugster E, Jahn H, Srikanth S, Scott SB, Richardson PJ, Everts RE, Ishkin A, Nikolsky Y, Resau JH, et al. Genomic characterization of explant tumorgraft models derived from fresh patient tumor tissue. J Transl Med. 2012; 10: 125. doi: 10.1186/1479-5876-10-125.

41. Nemati F, Sastre-Garau X, Laurent C, Couturier J, Mariani P, Desjardins L, Piperno-Neumann S, Lantz O, Asselain B, Plancher C, Robert D, Péguillet I, Donnadieu M-H, et al. Establishment and characterization of a panel of human uveal melanoma xenografts derived from primary and/or metastatic tumors. Clin Cancer Res. 2010; 16: 2352-62. doi: 10.1158/1078-0432.CCR-09-3066.

42. Lee W-S, Kim H-Y, Seok JY, Jang HH, Park YH, Kim S-Y, Shin DB, Hong S. Genomic profiling of patient-derived colon cancer xenograft models. Medicine (Baltimore). 2014; 93: e298. doi: 10.1097/MD.0000000000000298.

43. Chou J, Fitzgibbon MP, Mortales C-LL, Towlerton AMH, Upton MP, Yeung RS, McIntosh MW, Warren EH. Phenotypic and transcriptional fidelity of patient-derived colon cancer xenografts in immune-deficient mice. PLoS ONE. 2013; 8: e79874. doi: 10.1371/journal.pone.0079874.

44. Dangles-Marie V, Pocard M, Richon S, Weiswald L-B, Assayag F, Saulnier P, Judde J-G, Janneau J-L, Auger N, Validire P, Dutrillaux B, Praz F, Bellet D, et al. Establishment of human colon cancer cell lines from fresh tumors versus xenografts: comparison of success rate and cell line features. Cancer Res. 2007; 67: 398-407. doi: 10.1158/0008-5472.CAN-06-0594.

45. Ilie M, Nunes M, Blot L, Hofman V, Long-Mira E, Butori C, Selva E, Merino-Trigo A, Vénissac N, Mouroux J,
Vrignaud P, Hofman P. Setting up a wide panel of patientderived tumor xenografts of non-small cell lung cancer by improving the preanalytical steps. Cancer Med. 2015; 4: 201-11. doi: 10.1002/cam4.357.

46. Linnebacher M, Maletzki C, Ostwald C, Klier U, Krohn M, Klar E, Prall F. Cryopreservation of human colorectal carcinomas prior to xenografting. BMC Cancer. 2010; 10: 362. doi: 10.1186/1471-2407-10-362.

47. Bertotti A, Migliardi G, Galimi F, Sassi F, Torti D, Isella C, Corà D, Di Nicolantonio F, Buscarino M, Petti C, Ribero D, Russolillo N, Muratore A, et al. A molecularly annotated platform of patient-derived xenografts ("xenopatients") identifies HER2 as an effective therapeutic target in cetuximab-resistant colorectal cancer. Cancer Discov. 2011; 1: 508-23. doi: 10.1158/2159-8290.CD-11-0109.

48. Jin K, Li G, Cui B, Zhang J, Lan H, Han N, Xie B, Cao F, He K, Wang H, Xu Z, Teng L, Zhu T. Assessment of a novel VEGF targeted agent using patient-derived tumor tissue xenograft models of colon carcinoma with lymphatic and hepatic metastases. PLoS ONE. 2011; 6: e28384. doi: 10.1371/journal.pone.0028384.

49. Cho YB, Hong HK, Choi Y-L, Oh E, Joo KM, Jin J, Nam D-H, Ko Y-H, Lee WY. Colorectal cancer patient-derived xenografted tumors maintain characteristic features of the original tumors. J Surg Res. 2014; 187: 502-9. doi: 10.1016/j.jss.2013.11.010.

50. Kim MK, Osada T, Barry WT, Yang XY, Freedman JA, Tsamis KA, Datto M, Clary BM, Clay T, Morse MA, Febbo PG, Lyerly HK, Hsu DS. Characterization of an oxaliplatin sensitivity predictor in a preclinical murine model of colorectal cancer. Mol Cancer Ther. 2012; 11: 1500-9. doi: 10.1158/1535-7163.MCT-11-0937.

51. DeRose YS, Wang G, Lin Y-C, Bernard PS, Buys SS, Ebbert MTW, Factor R, Matsen C, Milash BA, Nelson E, Neumayer L, Randall RL, Stijleman IJ, et al. Tumor grafts derived from women with breast cancer authentically reflect tumor pathology, growth, metastasis and disease outcomes. Nat Med. 2011; 17: 1514-20. doi: 10.1038/nm.2454.

52. Kuesters S, Maurer M, Burger AM, Metz T, Fiebig HH. Correlation of ErbB2 gene status, mRNA and protein expression in a panel of $>100$ human tumor xenografts of different origin. Onkologie. 2006; 29: 249-56. doi: 10.1159/000093048.

53. Galimi F, Torti D, Sassi F, Isella C, Corà D, Gastaldi S, Ribero D, Muratore A, Massucco P, Siatis D, Paraluppi G, Gonella F, Maione F, et al. Genetic and expression analysis of MET, MACC1, and HGF in metastatic colorectal cancer: response to met inhibition in patient xenografts and pathologic correlations. Clin Cancer Res. 2011; 17: 314656. doi: 10.1158/1078-0432.CCR-10-3377.

54. Krumbach R, Schüler J, Hofmann M, Giesemann T, Fiebig $\mathrm{H}-\mathrm{H}$, Beckers T. Primary resistance to cetuximab in a panel of patient-derived tumour xenograft models: activation of MET as one mechanism for drug resistance. Eur J Cancer. 2011; 47: 1231-43. doi: 10.1016/j.ejca.2010.12.019. 
55. Jin K, Lan H, Cao F, Han N, Xu Z, Li G, He K, Teng L. Differential response to EGFR- and VEGF-targeted therapies in patient-derived tumor tissue xenograft models of colon carcinoma and related metastases. Int J Oncol. 2012; 41: 583-8. doi: 10.3892/ijo.2012.1469.

56. Bardelli A, Corso S, Bertotti A, Hobor S, Valtorta E, Siravegna G, Sartore-Bianchi A, Scala E, Cassingena A, Zecchin D, Apicella M, Migliardi G, Galimi F, et al. Amplification of the MET receptor drives resistance to antiEGFR therapies in colorectal cancer. Cancer Discov. 2013; 3: 658-73. doi: 10.1158/2159-8290.CD-12-0558.

57. Pechańska P, Becker M, Mayr T, Hinzmann B, Adams HP, Klaman I, Kretschmar KH, Kretschmar K, Stecker K, Mantke R, Pauli R, Pertschy J, Hertel K, et al. Mutation Status of KRAS, BRAF, PIK3CA and Expression Level of AREG and EREG Identify Responders to Cetuximab in a Large Panel of Patient Derived Colorectal Carcinoma Xenografts of All Four UICC Stages. JCT. 2013; 04: 67893. doi: 10.4236/jct.2013.42083.

58. Nunes M, Vrignaud $\mathrm{P}$, Vacher S, Richon S, Lievre A, Cacheux W, Weiswald L-B, Massonnet G, Chatean-Joubert S, Nicolas A, Dib C, Zhang W, Watters J, et al. Evaluating patient-derived colorectal cancer-xenografts as preclinical models by comparison with patient clinical data. Cancer Res. 2015. doi: 10.1158/0008-5472.CAN-14-1590.

59. Bieche I, Vacher S, Vallerand D, Richon S, Hatem R, De Plater L, Dahmani A, Nemati F, Angevin E, Marangoni E, Roman-Roman S, Decaudin D, Dangles-Marie V. Vasculature analysis of patient derived tumor xenografts using species-specific PCR assays: evidence of tumor endothelial cells and atypical VEGFA-VEGFR1/2 signalings. BMC Cancer. 2014; 14: 178. doi: 10.1186/14712407-14-178.

60. Zanella ER, Galimi F, Sassi F, Migliardi G, Cottino F, Leto SM, Lupo B, Erriquez J, Isella C, Comoglio PM, Medico E, Tejpar S, Budinská E, et al. IGF2 is an actionable target that identifies a distinct subpopulation of colorectal cancer patients with marginal response to anti-EGFR therapies. Sci Transl Med. 2015; 7: 272ra12-2. doi: 10.1126/ scitranslmed.3010445.

61. Fichtner I, Slisow W, Gill J, Becker M, Elbe B, Hillebrand T, Bibby M. Anticancer drug response and expression of molecular markers in early-passage xenotransplanted colon carcinomas. Eur J Cancer. 2004; 40: 298-307.

62. Migliardi G, Sassi F, Torti D, Galimi F, Zanella ER, Buscarino M, Ribero D, Muratore A, Massucco P, Pisacane A, Risio M, Capussotti L, Marsoni S, et al. Inhibition of MEK and PI3K/mTOR suppresses tumor growth but does not cause tumor regression in patient-derived xenografts of RAS-mutant colorectal carcinomas. Clin Cancer Res. 2012; 18: 2515-25. doi: 10.1158/1078-0432.CCR-11-2683.

63. Dong X, Jin K, Hu X, Du F, Lan H, Han N, Ma Z, Xie B, Cui B, Teng L, Cao F. Antitumor effect of FP3 in combination with cetuximab on patient-derived tumor tissue xenograft models of primary colon carcinoma and related lymphatic and hepatic metastases. Int J Mol Med. 2012; 30: 126-32. doi: 10.3892/ijmm.2012.968.

64. Jin K, Lan H, Xie B, He K, Xu Z, Li G, Han N, Teng L, Cao F. Antitumor effects of FP3 in combination with capecitabine on PDTT xenograft models of primary colon carcinoma and related lymphatic and hepatic metastases. Cancer Biol Ther. 2012; 13: 737-44. doi: 10.4161/ cbt.20556.

65. Chiron M, Bagley RG, Pollard J, Mankoo PK, Henry C, Vincent L, Geslin C, Baltes N, Bergstrom DA. Differential Antitumor Activity of Aflibercept and Bevacizumab in Patient-Derived Xenograft Models of Colorectal Cancer. Mol Cancer Ther. 2014; 13: 1636-44. doi: 10.1158/15357163.MCT-13-0753.

66. Schmieder R, Hoffmann J, Becker M, Bhargava A, Müller T, Kahmann N, Ellinghaus P, Adams R, Rosenthal A, Thierauch K-H, Scholz A, Wilhelm SM, Zopf D. Regorafenib (BAY 73-4506): antitumor and antimetastatic activities in preclinical models of colorectal cancer. Int $\mathrm{J}$ Cancer. 2014; 135: 1487-96. doi: 10.1002/ijc.28669.

67. Mischek D, Steinborn R, Petznek H, Bichler C, Zatloukal K, Stürzl M, Günzburg WH, Hohenadl C. Molecularly characterised xenograft tumour mouse models: valuable tools for evaluation of new therapeutic strategies for secondary liver cancers. J Biomed Biotechnol. 2009; 2009: 437284-13. doi: 10.1155/2009/437284.

68. Weiswald L-B, Richon S, Massonnet G, Guinebretière J-M, Vacher S, Laurendeau I, Cottu P, Marangoni E, Nemati F, Validire P, Bellet D, Bièche I, Dangles-Marie V. A shortterm colorectal cancer sphere culture as a relevant tool for human cancer biology investigation. Br J Cancer. 2013; 108: 1720-31. doi: 10.1038/bjc.2013.132.

69. Linnebacher M, Maletzki C, Klier U, Klar E. Bacterial immunotherapy of gastrointestinal tumors. Langenbecks Arch Surg. 2012; 397: 557-68. doi: 10.1007/s00423-0110892-6.

70. McGranahan N, Swanton C. Biological and therapeutic impact of intratumor heterogeneity in cancer evolution. Cancer Cell. 2015; 27: 15-26. doi: 10.1016/j. ccell.2014.12.001.

71. Gustavsson B, Carlsson G, Machover D, Petrelli N, Roth A, Schmoll H-J, Tveit K-M, Gibson F. A Review of the Evolution of Systemic Chemotherapy in the Management of Colorectal Cancer. Clin Colorectal Cancer. 2015; 14: 1-10. doi: 10.1016/j.clcc.2014.11.002.

72. Whittle JR, Lewis MT, Lindeman GJ, Visvader JE. Patient-derived xenograft models of breast cancer and their predictive power. Breast Cancer Res. 2015; 17: 17. doi: 10.1186/s13058-015-0523-1.

73. Rosfjord E, Lucas J, Li G, Gerber H-P. Advances in patient-derived tumor xenografts: from target identification to predicting clinical response rates in oncology. Biochem Pharmacol. 2014; 91: 135-43. doi: 10.1016/j. bcp.2014.06.008. 
74. Landis SC, Amara SG, Asadullah K, Austin CP, Blumenstein R, Bradley EW, Crystal RG, Darnell RB, Ferrante RJ, Fillit H, Finkelstein R, Fisher M, Gendelman $\mathrm{HE}$, et al. A call for transparent reporting to optimize the predictive value of preclinical research. Nature. 2012; 490: 187-91. doi: 10.1038/nature11556.

75. Henderson VC, Kimmelman J, Fergusson D, Grimshaw JM, Hackam DG. Threats to validity in the design and conduct of preclinical efficacy studies: a systematic review of guidelines for in vivo animal experiments. PLoS Med. 2013; 10: e1001489.

76. Zhou Q, Facciponte J, Jin M, Shen Q, Lin Q. Humanized NOD-SCID IL2rg-/- mice as a preclinical model for cancer research and its potential use for individualized cancer therapies. Cancer Lett. 2014; 344: 13-9. doi: 10.1016/j. canlet.2013.10.015.
77. Yokota SJ, Facciponte JG, Kelleher RJ, Shultz LD, Loyall JL, Parsons RR, Odunsi K, Frelinger JG, Lord EM, Gerber $\mathrm{SA}$, Balu-Iyer SV, Bankert RB. Changes in ovarian tumor cell number, tumor vasculature, and $\mathrm{T}$ cell function monitored in vivo using a novel xenograft model. Cancer Immun. 2013; 13: 11.

78. Simpson-Abelson MR, Sonnenberg GF, Takita H, Yokota SJ, Conway TF, Kelleher RJ, Shultz LD, Barcos M, Bankert RB. Long-term engraftment and expansion of tumorderived memory $\mathrm{T}$ cells following the implantation of non-disrupted pieces of human lung tumor into NOD-scid IL2Rgamma(null) mice. J Immunol. 2008; 180: 7009-18.

79. Wang J, Reiss KA, Khatri R, Jaffee E, Laheru D. Immune Therapy in GI Malignancies: A Review. J Clin Oncol. 2015; 33: 1745-53. doi: 10.1200/JCO.2015.60.7879. 